Supporting Information for

\title{
Photodegradable Polymer Capsules Fabricated via Interfacial Photo-crosslinking of Spherical Polymer Particles
}

Yukiya Kitayama $^{1 *}$, Toshifumi Takeuchi ${ }^{2}$

1: Graduate School of Engineering, Osaka Prefecture University, 1-1, Gakuen-cho, Naka-ku, Sakai, Osaka 599-8531, Japan

2: Graduate School of Engineering, Kobe University, 1-1, Rokkodai-cho, Nada-ku, Kobe 657-8501, Japan

Corresponding Author

*Yukiya Kitayama

Email: kitayama@chem.osakafu-u.ac.jp 


\section{Experimental section}

\section{1-1. Materials}

Methyl methacrylate (MMA), n-butyl methacrylate (BMA) sodium chloride ( $\mathrm{NaCl})$, potassium carbonate $\left(\mathrm{K}_{2} \mathrm{CO}_{3}\right)$, tetrahydrofuran (THF), magnesium sulfate $\left(\mathrm{MgSO}_{4}\right)$, Rhodamine $\mathrm{B}$, and dichloromethane (DCM) were purchased from Nacalai Tesque Co. (Kyoto, Japan). Methacryloyl chloride, 2-bromoethanol, 7-hydroxy coumarin and glycidyl methacrylate (GMA) were purchased from Tokyo Chemical Industries (Tokyo, Japan). Ethyl acetate (EtOAc), acetone, chloroform, dimethyl sulfoxide (DMSO), 2,2'-azobisisobutyronitrile (AIBN), sodium hydrogen carbonate $\left(\mathrm{NaHCO}_{3}\right)$, hexane (Hex), citric acid, toluene, pyridine, and poly(vinyl alcohol) (PVA; degree of polymerization: 1000, degree of saponification: 88\%) were purchased from Wako Pure Chemical Co., Ltd (Osaka, Japan). Quartz substrate (10 mm $\times 12$ mm) was purchased from Matsunami Glass Ind. Ltd. (Osaka, Japan) Deionized water used was obtained from a Millipore Milli-Q purification system. Fluorescein acrylamide (FAm) were prepared by the reported procedures. ${ }^{1}$

\section{1-2. Apparatus}

UV-Vis spectral measurements were conducted using a V-560 spectrophotometer (JASCO Ltd., Tokyo, Japan). ${ }^{1} \mathrm{H}-\mathrm{NMR}$ spectra were measured using a $300-\mathrm{MHz}$ FT-NMR apparatus 
(JNM-LA300 FT-NMR system, JEOL Ltd., Tokyo, Japan). A C2si confocal laser scanning microscope (CLSM, Nikon Corp., Tokyo Japan) with excitation at $488 \mathrm{~nm}$ (for FAm) or $543 \mathrm{~nm}$ (for Rhodamine B) and emission bandpass filters at 499-529 nm (for FAm) or 552-617 nm (for Rhodamine B). An objective lens was $\times 40$. The limit of resolution for optical microscope is generally known as less than sub- $\mu \mathrm{m}$ region since the resolution depends on the light wavelength and numerical aperture (NA). In this study, visible light and $\times 40$ objective lens (NA: 0.95 ) were used in the optical microscope, and the resolution is estimated to be approximately $350 \mathrm{~nm}$ (wavelength: $550 \mathrm{~nm}$ ) from the following equation. Therefore the shell thickness of hollow polymer particles with over sub- $\mu \mathrm{m}$ region thickness can be analyzed by the optical microscope.

$$
\text { Resolution }=\frac{0.61 \times \lambda}{N A}
$$

Number-average and weight-average molecular weights $\left(M_{\mathrm{n}}\right.$ and $\left.M_{\mathrm{w}}\right)$ were analyzed via gel permeation chromatography (GPC) at $40^{\circ} \mathrm{C}$ using two poly(styrene-co-divinylbenzene) gel columns (Tosoh Corp., TSK gel GMHHR-H, $7.8 \mathrm{~mm}$ i.d. $\times 300 \mathrm{~mm}$ ) with THF as the eluent, a flow rate of $1.0 \mathrm{~mL} \mathrm{~min}^{-1}$, a refractive index (RI) detector (TOSOH RI-8020/21), and an ultraviolet (UV) detector (TOSOH UV- 8II). The columns were calibrated with polystyrene calibration standards (molecular weights $=1.05 \times 10^{3}$ to $\left.5.48 \times 10^{6}, M_{\mathrm{w}} / M_{\mathrm{n}}=1.01-1.15\right)$. 


\section{1-3. Synthesis of COMA}<smiles>C=C(C)C(=O)OCCOc1ccc2ccc(=O)oc2c1</smiles>

Scheme S1 Synthetic procedure of COMA

\section{1-3-1. 7-(2-hydroxy ethoxy) coumarin (Compound 2)}

2-Bromoethanol (0.68 mL, $9.5 \mathrm{mmol}$ ), 7-hydroxy coumarin (Compound 1) (1.05 g, $6.5 \mathrm{mmol}$ ), and $\mathrm{K}_{2} \mathrm{CO}_{3}(4.16 \mathrm{~g}, 30 \mathrm{mmol})$ were reacted in acetone $(25 \mathrm{~mL})$ under reflux for $30 \mathrm{~h}$. After filtration, the solvent was evaporated in vacuo. The crude product was purified by silica gel chromatography (AI-580S, Yamazen Corporation, Osaka, Japan) (Hex:EtOAc $=70: 30-0: 100$ $\mathrm{v} / \mathrm{v})$, and the obtained white product was dried in vacuo.

Yield $=0.84 \mathrm{~g}(63 \%) .{ }^{1} \mathrm{H}$ NMR $\left(300 \mathrm{MHz}, \mathrm{CDCl}_{3}, \delta\right)$ 7.66-7.63 (d, 1H, coumarin), 7.40-7.38 (d, $1 \mathrm{H}$, coumarin), 6.93-6.83 (m, 2H, coumarin), 6.29-6.25 (d, $1 \mathrm{H}$, coumarin), 4.17-4.14 (t, $2 \mathrm{H}$, ethyl), 4.05-4.00 (t, $2 \mathrm{H}$, ethyl), 2.20-2.16 (t, $1 \mathrm{H}, \mathrm{OH})$. 


\section{1-3-2. 7-(2-Methacryloyloxy ethoxy) coumarin (COMA) (3)}

7-(2-Hydroxy ethoxy) coumarin (compound 2) $(0.83 \mathrm{~g}, 4.1 \mathrm{mmol})$ and pyridine $(1.07 \mathrm{~mL}, 9$ mmol) were dissolved in THF (40 mL). Methacryloyl chloride $(0.48 \mathrm{~mL}, 4.3 \mathrm{mmol})$ dissolved in THF (20 mL) was slowly added into the solution under cooling in ice, and the mixture was reacted room temperature at $12 \mathrm{~h}$. After filtration, the obtained solution was washed with $\mathrm{NaCl}$ aqueous solution, citric acid aqueous solution, and $\mathrm{NaHCO}_{3}$ aqueous solution. After drying with $\mathrm{MgSO}_{4}$, the solvent was evaporated. The crude product was purified with by silica gel chromatography $($ Hex:EtOAc $=100: 0-50: 50 \mathrm{v} / \mathrm{v})$, and the obtained product was dried in vacuo.

Yield $=0.73 \mathrm{~g}(65 \%) .{ }^{1} \mathrm{H}$ NMR $\left(300 \mathrm{MHz}, \mathrm{CDCl}_{3}, \delta\right)$ 7.66-7.63 (d, 1H, coumarin), 7.41-7.38 (d, $1 \mathrm{H}$, coumarin), 6.89-6.81 (m, 2H, coumarin), 6.29-6.26 (d, 1H, coumarin), $6.15(\mathrm{~s}, 1 \mathrm{H}$, vinyl), $5.61\left(\mathrm{~s}, 1 \mathrm{H}\right.$, vinyl), 4.55-4.52 (t, 2H, ethyl), 4.31-4.24 (t, 2H, ethyl), $1.98\left(\mathrm{~s}, 3 \mathrm{H},-\mathrm{CH}_{3}\right)$.

\section{1-4. Photo-irradiation of $\mathrm{P}(\mathrm{COMA}-\mathrm{MMA})-33$ film}

DCM solution of $\mathrm{P}(\mathrm{COMA}-\mathrm{MMA})-33(1 \mathrm{mg} / \mathrm{mL}, 20 \mu \mathrm{L})$ was dropped on a quartz substrate and solvent was evaporated. After further drying in vacuo, the photo-irradiation ( $\lambda=365 \mathrm{~nm})$ was carried out to the substrate for various photo-irradiation time, and the UV-Vis 
measurement was carried out for the film. The photo-irradiation powers were $9 \mathrm{~mW} / \mathrm{cm}^{2}$. The shorter wavelength light $\left(\lambda=254 \mathrm{~nm}, 2 \mathrm{~mW} / \mathrm{cm}^{2}\right.$.) was also demonstrated to the film.

\section{1-5. Capsule particles}

The shell-crosslinked hollow $\mathrm{P}(\mathrm{COMA}-\mathrm{MMA})-33$ particles dispersed in DMSO $(0.9 \mathrm{~mL})$ were mixed with a DMSO solution of Rhodamine B (final concentration: $1 \mathrm{mg} / \mathrm{mL}, 0.1 \mathrm{~mL}$ ). Then, the solvent was replaced with water $(1 \mathrm{~mL})$ after centrifugation of the hollow polymer particles. The particles were washed with pure water by centrifugation five times to remove non-loaded free Rhodamine B. To load FAm into the hollow particles, we used the same procedure as above. 
2. UV-Vis spectrum of COMA
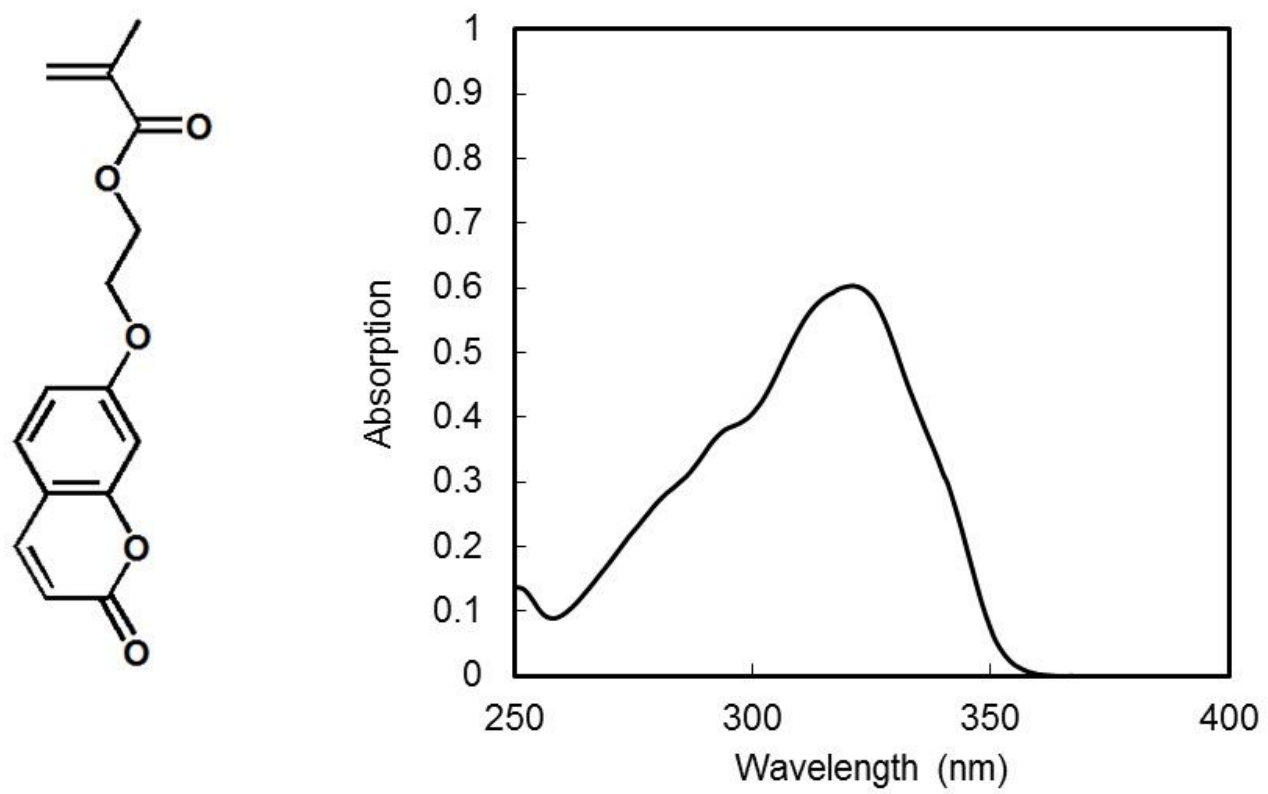

Figure S1. UV-Vis spectrum of new photo-reactive monomer COMA. 


\section{3. ${ }^{1}$ H-NMR spectrum of P(COMA-MMA)-33}
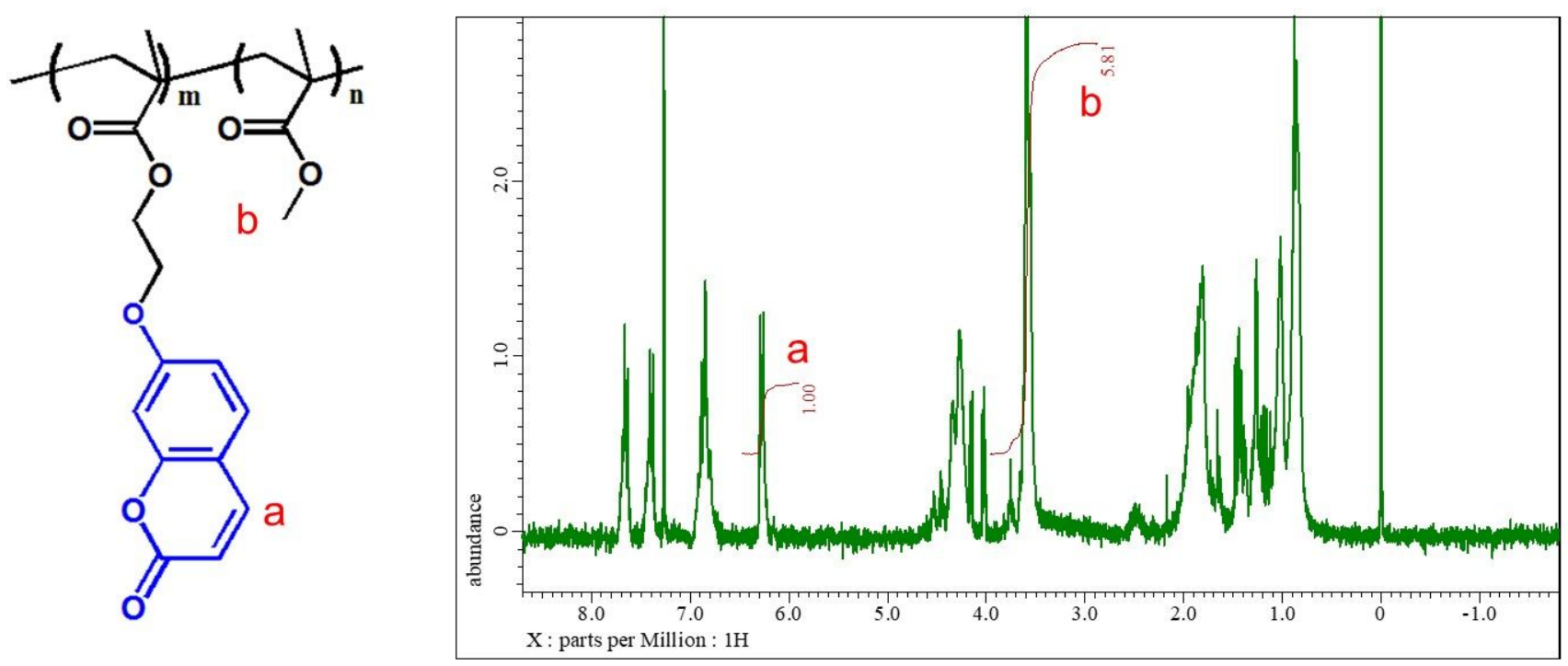

Figure S2. ${ }^{1} \mathrm{H}-\mathrm{NMR}$ spectrum of P(COMA-MMA)-33. 
4. UV-Vis spectrum of $\mathrm{P}(\mathrm{COMA-MMA)-33}$
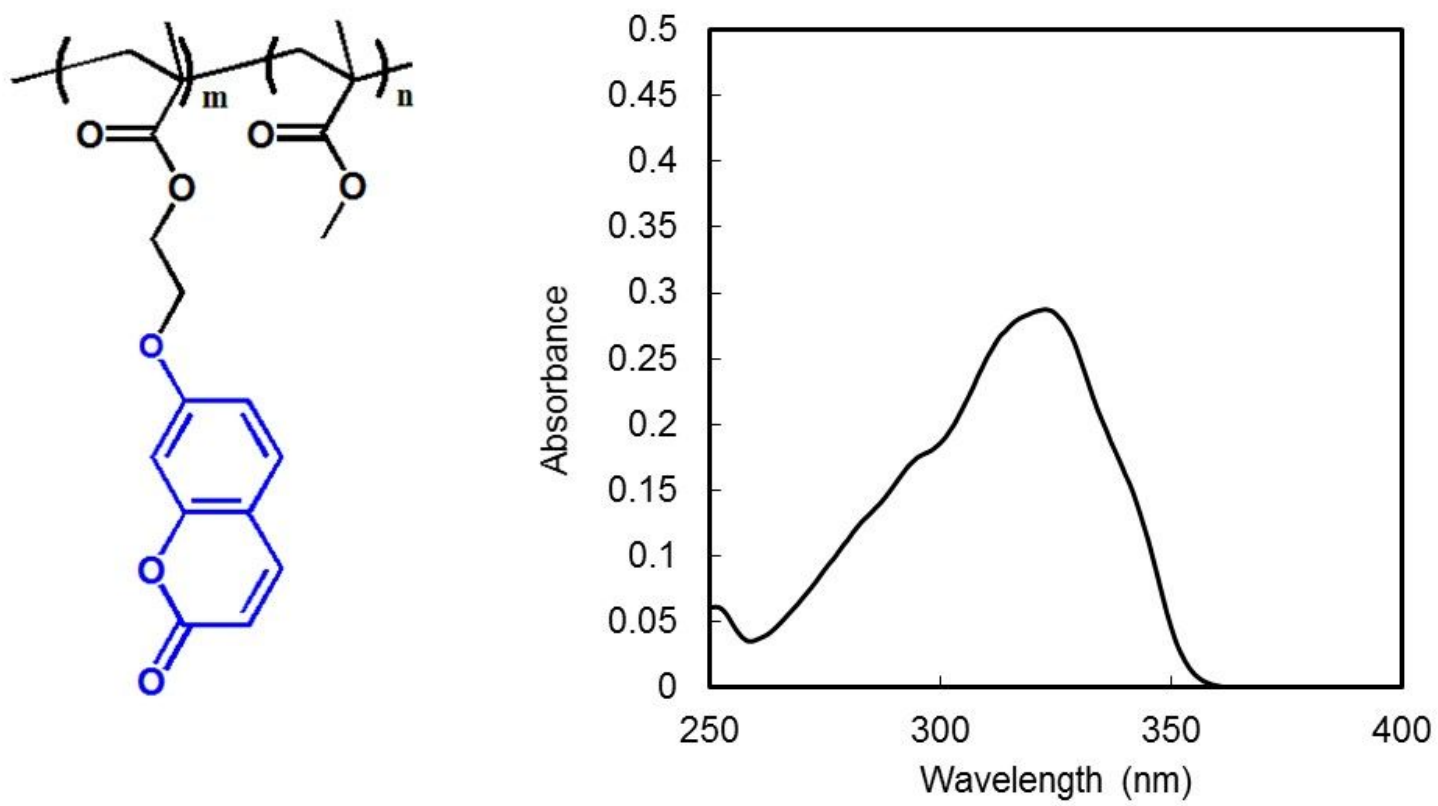

Figure S3. UV-Vis spectrum of $\mathrm{P}(\mathrm{COMA}-\mathrm{MMA})-33$. 
5. ${ }^{1}$ H-NMR spectra of P(COMA-BMA)-33 and P(COMA-GMA)-33

(a)
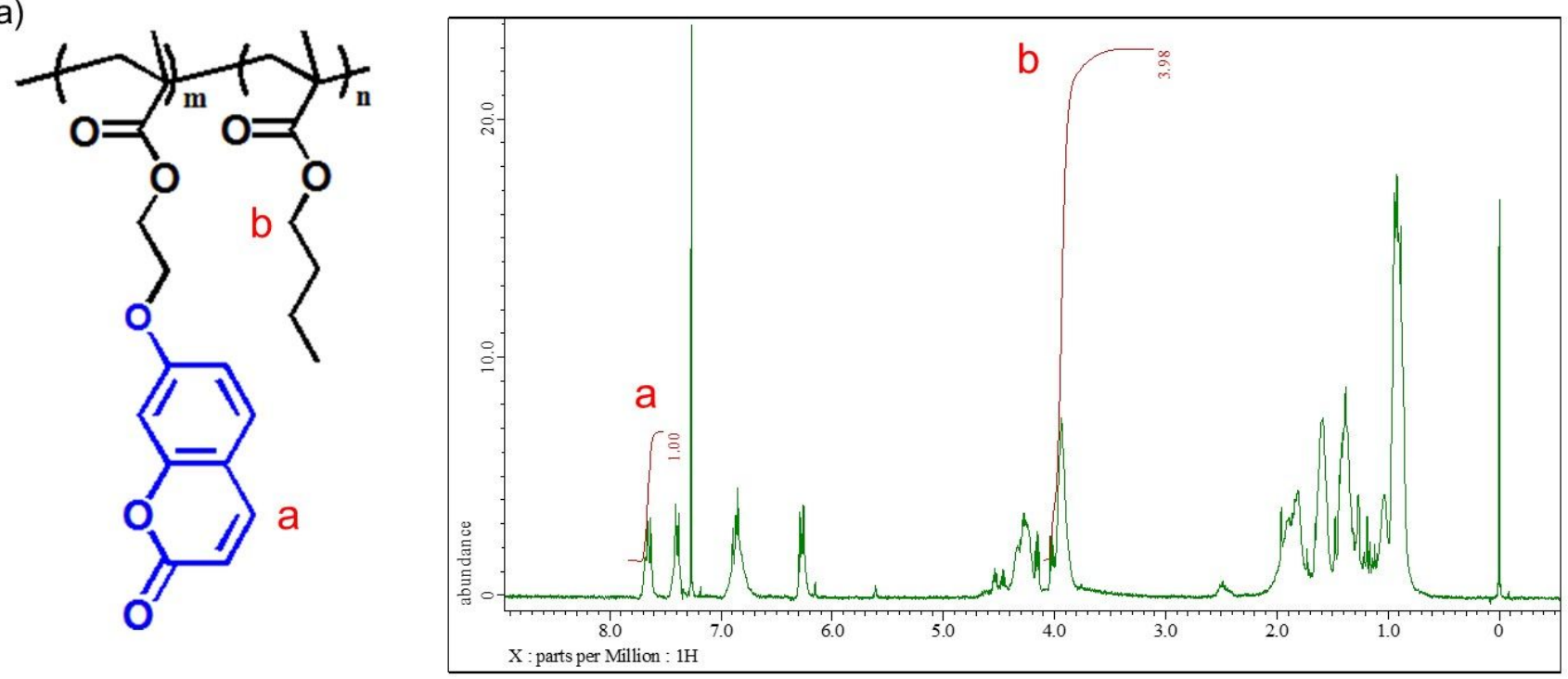

(b)
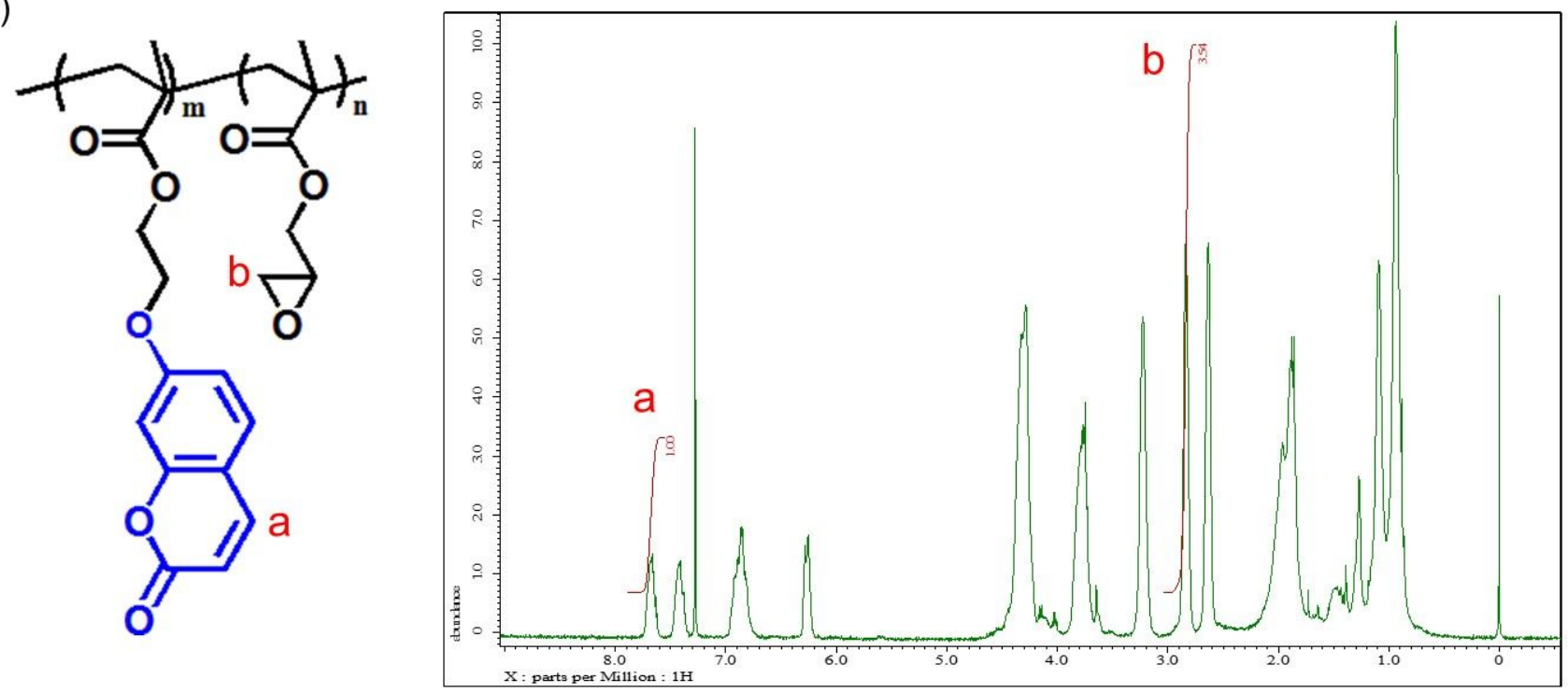

Figure S4. UV-Vis spectra of $\mathrm{P}(\mathrm{COMA}-\mathrm{BMA})-33$ (a) and P(COMA-GMA)-33 (b). 
6. UV-Vis spectra of $\mathrm{P}(\mathrm{COMA-BMA)-33}$ and $\mathrm{P}(\mathrm{COMA-GMA)-33}$
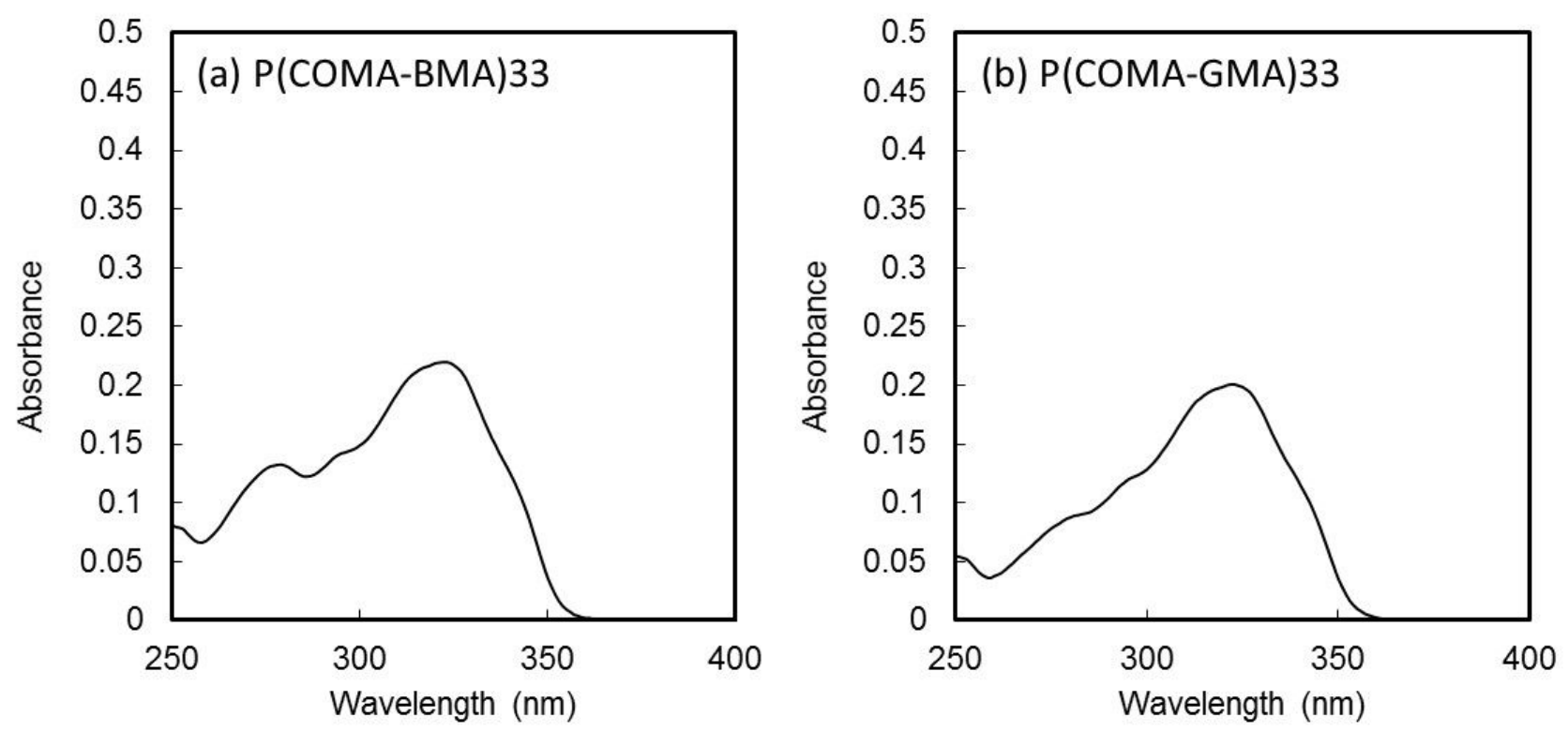

Figure S5. UV-Vis spectra of P(COMA-BMA)-33 (a) and P(COMA-GMA)-33 (b). 


\section{Reaction Rate of Interfacial Photocrosslinking}

Shell-crosslinked P(COMA-MMA)-33 hollow particles were prepared by interfacial photo-crosslinking for $90 \mathrm{~min}\left(\lambda=365 \mathrm{~nm}, 9 \mathrm{~mW} / \mathrm{cm}^{2}\right)$. The photo-irradiated particles were collected by centrifugation. THF $(1 \mathrm{~mL})$ was added to the particles to dissolve the non-crosslinked polymers. The supernatant was collected by centrifugation. After 100 times dilution, the absorbance derived from non-crosslinked P(COMA-MMA)-33 was measured by UV-Vis, and the reaction rate of the interfacial photocrosslinking was estimated.

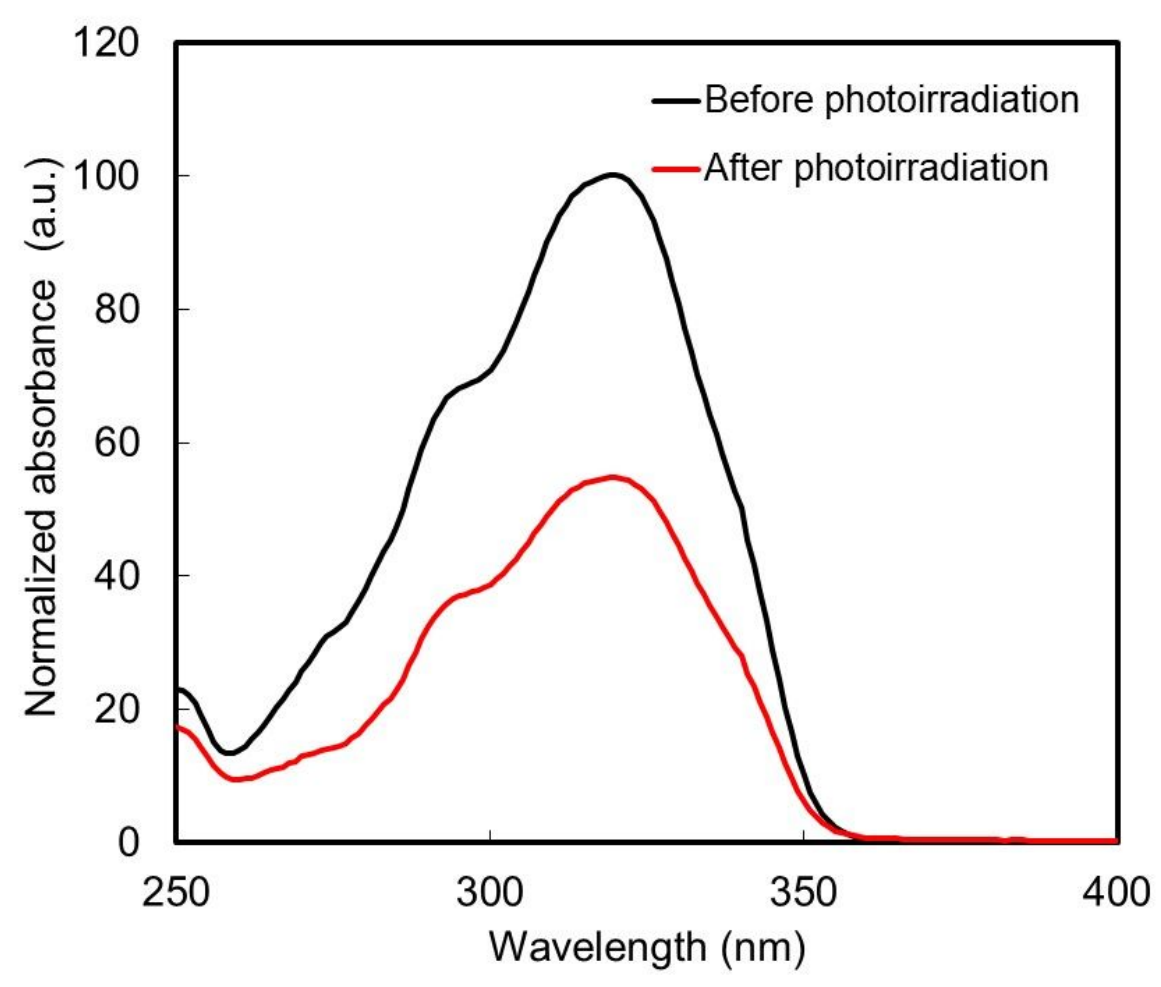

Figure S6. Absorbance derived from non-crosslinked P(COMA-MMA)-33 in the supernatant of THF dispersion of shell-crosslinked polymer particles, which was prepared by interfacial photocrosslinking $(\lambda=365 \mathrm{~nm})$ for $90 \mathrm{~min}$. 


\section{UV-Vis spectra of P(COMA-BMA)-33 and P(COMA-GMA)-33}
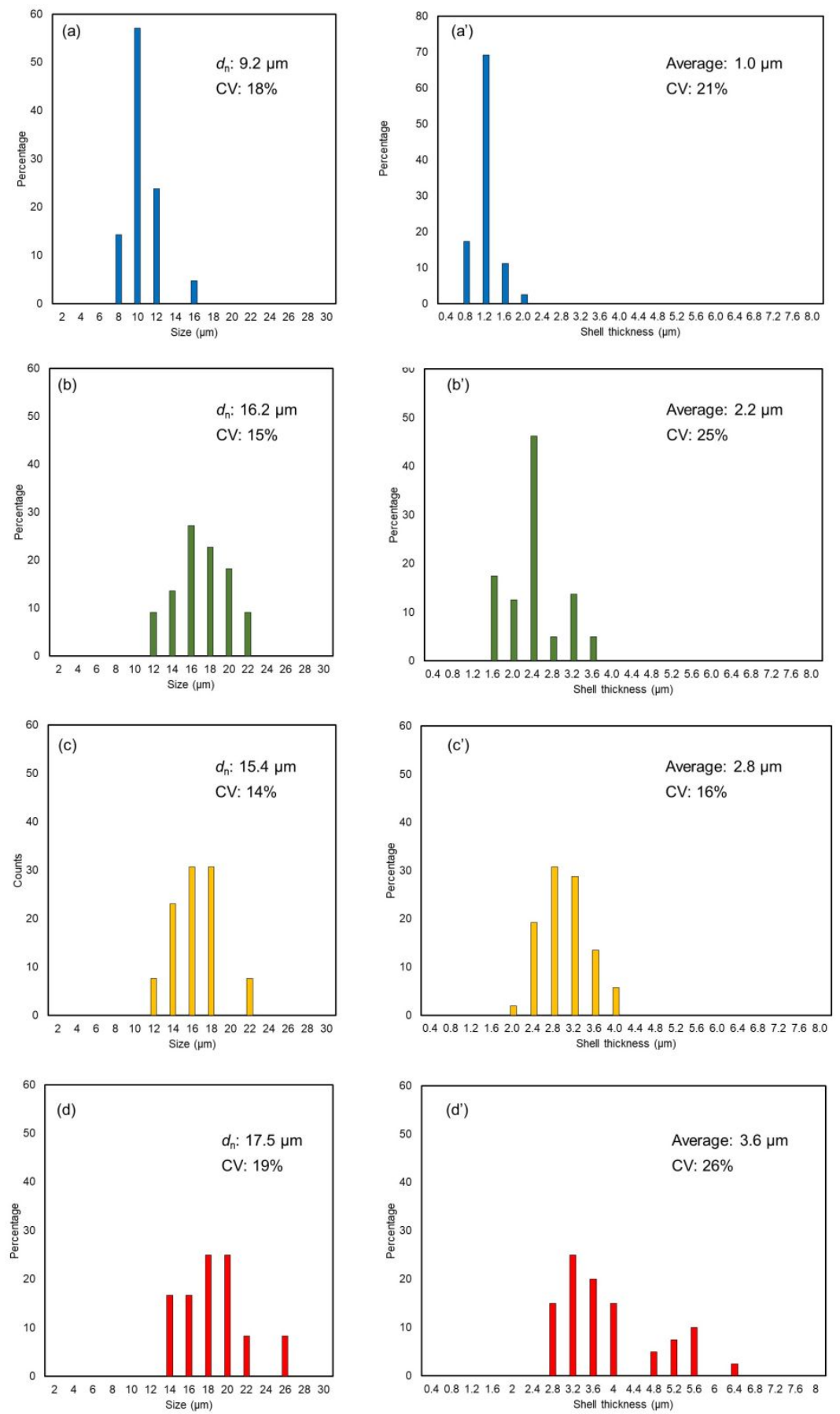

Figure S7. Particle size distributions (a-d) and shell-thickness distribution (a'-d') of shell-crosslinked hollow P(COMA-MMA)-33 particles prepared with different photoirradiation times. Shell thickness measurements were performed four times for each particle due to the inhomogeneity of the shell thickness. Photoirradiation time: (a) $30 \mathrm{~min}$; (b) $45 \mathrm{~min}$; (c) $60 \mathrm{~min}$; (d) $90 \mathrm{~min}$. The number of analyzed particles: (a) 21; (b) 20; (c) 13; (d) 12. 


\section{UV-Vis spectra of degraded $\mathrm{P}(\mathrm{COMA-MMA)-33} \mathrm{in} \mathrm{supernatant}$}

Shell-crosslinked P(COMA-MMA)-33 hollow particles were prepared by interfacial photo-crosslinking for $90 \mathrm{~min}\left(\lambda=365 \mathrm{~nm}, 9 \mathrm{~mW} / \mathrm{cm}^{2}\right)$ and subsequent removal of non-crosslinked polymer using THF. The hollow particles were then dispersed in pure THF $(5 \mathrm{~mL})$ in a glass vial. The particle dispersion was photoirradiated $\left(\lambda=254 \mathrm{~nm}, 2 \mathrm{~mW} / \mathrm{cm}^{2}\right)$ under gentle stirring. After various photoirradiation times, the sample $(200 \mu \mathrm{L})$ was collected and the supernatant $(100 \mu \mathrm{L})$ was obtained by centrifugation. As a control experiment, the particle dispersion was stirred under dark. After ten times dilution of the supernatant, absorbance at $320 \mathrm{~nm}$ derived from degraded P(COMA-MMA)-33 containing free coumarin groups from shell-crosslinked hollow particles was measured by UV-Vis.

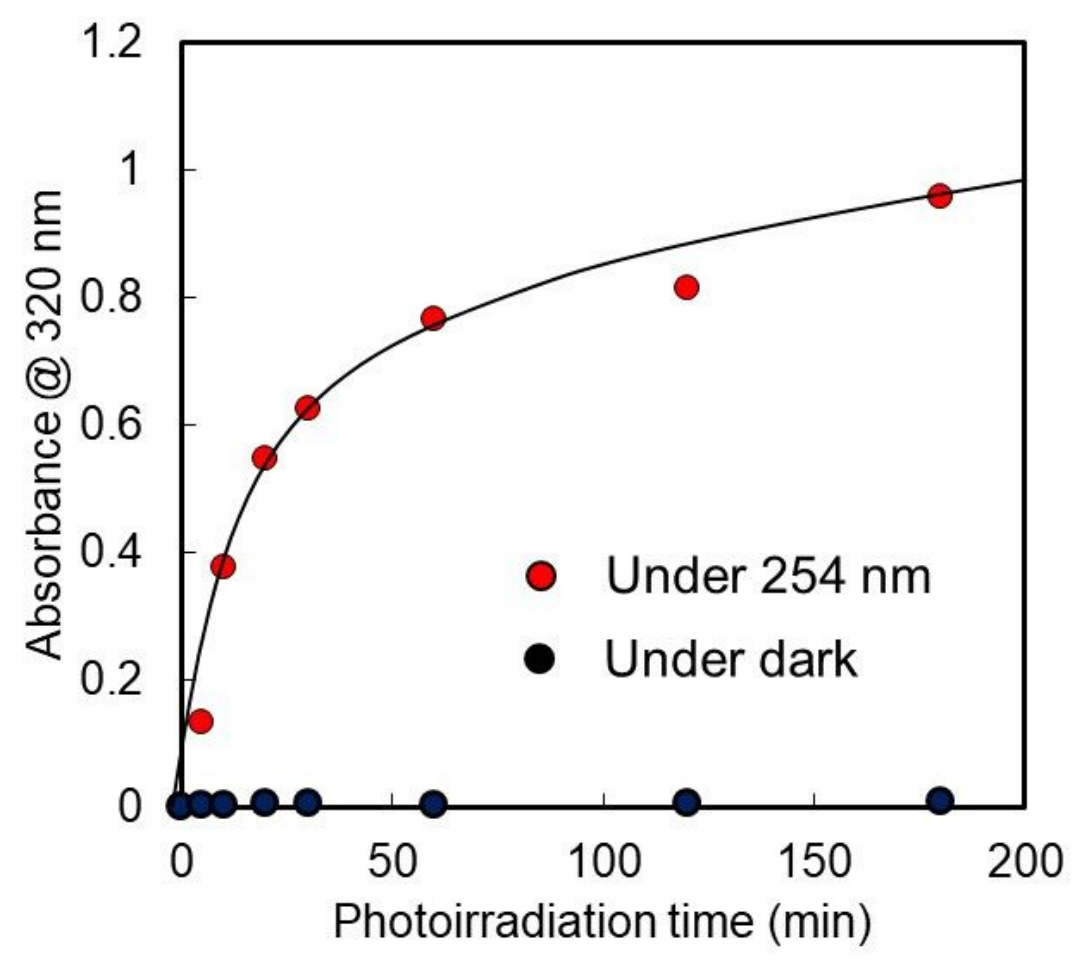

Figure S8. Absorbance derived from degraded P(COMA-MMA)-33 from the shell-crosslinked hollow polymer particles in supernatant after photoirradiation $(\lambda=254 \mathrm{~nm})$ with various irradiation times (red). As a control, the particle dispersion was stirred under dark (black). 


\section{Reference}

(1) Takeuchi, T.; Kitayama, Y.; Sasao, R.; Yamada, T.; Toh, K.; Matsumoto, Y.; Kataoka, K. Molecularly Imprinted Nanogels Acquire Stealth In Situ by Cloaking Themselves With Native Dysopsonic Proteins, Angew. Chem. Int. Ed. 2017, 56, 7088. 